\title{
Português Língua Estrangeira na China: o ensino remoto emergencial nos primeiros tempos de Covid-19
}

\author{
Manuel João Pires* \\ Resumo
}

Em um tempo em que os meios on-line adquiriram um súbito e preponderante lugar de destaque como plataforma de trabalho das instituições de ensino à escala mundial, o ensino de português na China não foi exceção. As contingências da epidemia na China fizeram com que fosse precursora nessa experiência, uma vez que a implementação de aulas on-line no ensino superior chinês iniciou-se semanas antes de a Covid-19 ter sido declarada uma pandemia pela Organização Mundial de Saúde. O presente estudo tem como objetivo analisar as decorrências do ensino remoto emergencial e o seu impacto na aprendizagem dos alunos durante esse período sensível. Para esse efeito, foram realizados questionários e entrevistas a estudantes universitários de português que cursaram as aulas on-line e que expressaram as suas perspetivas sobre os contratempos e as mais-valias dessa experiência. Tendo em consideração que a introdução do ensino on-line, nessa data, não resultou de planejamento, estruturação ou intenção prévia, mas foi fruto de contingências de ordem excepcional, as conclusões deste estudo incidem nas medidas positivas que se podem retirar dessa experiência de ensino e que futuramente poderão ser implementadas com a devida organização e concertação com vista a enriquecer e dinamizar o ensino-aprendizagem de Português Língua Estrangeira na China.

Palavras-chave: Português Língua Estrangeira. China. Ensino Remoto Emergencial. Covid-19.

Leitor de Português na Universidade de Sun Yat-sen. Doutorando em Estudos Culturais na Universidade de Lisboa. ORCID: 0000-0002-1242-5319. 


\section{Portugués como Lengua Extranjera en China: la enseñanza remota de emergencia en los primeros días de Covid-19}

\section{Resumen}

En una época en la que los medios on-line adquirieron un lugar prominente como plataforma de trabajo para instituciones educativas de todo el mundo, la enseñanza del portugués en China no fue una excepción. Las contingencias de la epidemia en China la convirtieron en precursora de esta experiencia, ya que la implementación de clases on-line en la educación superior china comenzó semanas antes de que la Organización Mundial de la Salud declarara pandemia al Covid-19. El presente estudio tiene como objetivo analizar las consecuencias de enseñanza remota de emergencia y su impacto en el aprendizaje de los estudiantes durante este período delicado. Para ello, se realizaron cuestionarios y entrevistas a estudiantes universitarios de portugués que tomaron clases on-line y que expresaron sus puntos de vista sobre los inconvenientes y ventajas de esta experiencia. Teniendo en cuenta que la implantación de la enseñanza remota, en esa fecha, no fue fruto de una planificación, estructuración o intención previa, sino que de contingencias excepcionales, las conclusiones de este estudio se centran en las medidas positivas que se pueden extraer de este experiencia docente y que en el futuro se pueden implementar con la debida organización y concertación con miras a enriquecer e impulsar la enseñanza y el aprendizaje del Portugués como Lengua Extranjera en China.

Palabras-clave: Portugués como Lengua Extranjera. China. Enseñanza Remota de Emergencia. Covid-19.

Recebido em: 23/02/2021 // Aceito em: 30/03/2021. 


\section{Introdução}

Os tempos de pandemia colocaram um desafio sem precedentes a todas as instituições escolares, uma vez que o ensino remoto se tornou subitamente a principal e única forma de ensino decretada pelos Ministérios de Educação de vários países com o apoio de várias organizações internacionais (FERRI; GRIFONI; GUZZO, 2020, p. 3), em uma altura em que grande parte da população mundial entrou em quarentena devido à pandemia da Covid-19 e cujas medidas de confinamento afetaram cerca de $90 \%$ da população estudantil em escala mundial (UNESCO, 2020a). Essa situação fez com que instituições, professores e alunos não tivessem tido tempo para treinamento ou especialização prévia de forma a preparar e estruturar essa nova forma de interação. Os agentes do processo de ensino e aprendizagem encontraram-se na circunstância de terem de descobrir e explorar, conjuntamente e em tempo real, novos métodos e plataformas de ensino.

No caso particular do ensino superior da China, as aulas on-line começaram a ser implementadas algum tempo antes de a Organização Mundial de Saúde declarar a Covid-19 como pandemia, a 12 de março de 2020. O Ministério da Educação chinês anunciou oficialmente, a 5 de fevereiro de 2020, orientações para as instituições de ensino superior implementarem o ensino on-line, em cooperação com as autoridades locais e nacionais, durante o período de confinamento dedicado à prevenção e controlo da epidemia. Segundo Zhu e Liu (2020, p. 696), essas diretivas recomendaram o reconhecimento das horas de trabalho on-line do professor como equivalentes à carga horária das aulas presenciais, fomentaram a procura de maior autonomia com os métodos de ensino digitais por parte de professores e alunos e 
incentivaram as universidades a desenvolverem estratégias de avaliação e creditação da aprendizagem on-line dos alunos. Foi nesse âmbito que, após o adiamento por duas semanas do segundo semestre do ano letivo 2019/2020, as aulas do ensino superior chinês foram restabelecidas no dia 24 de fevereiro de 2020, sob a forma de ensino on-line para fazer face às medidas de contenção em vigor.

$\mathrm{O}$ ensino de português nas universidades da China não foi exceção e passou pela mesma necessidade de adaptação a um novo e contingencial paradigma de ensino em que professores e alunos aprenderam em conjunto a trabalhar e a conviver em modo exclusivamente digital. O presente estudo debruça-se sobre a influência do ensino remoto emergencial na aprendizagem dos estudantes de português na Universidade de Sun Yat-sen, situada na província chinesa de Cantão. Para esse fim, foram recolhidas as perspetivas dos estudantes de uma turma do segundo ano de português da referida universidade para analisar o impacto desses primeiros tempos de ensino remoto motivado pela Covid-19. Desse modo, os objetivos deste estudo são: compreender as particularidades da aprendizagem de Português Língua Estrangeira na China durante a primeira experiência mundial de ensino remoto emergencial causada pela epidemia de Covid-19; perscrutar as principais dificuldades encontradas pelos alunos nesse processo; analisar a interação entre professor e aluno no ensino remoto; compreender as mais-valias dessa experiência de ensino na perspetiva dos alunos; analisar os procedimentos que podem ser retirados dessa experiência e aplicados para além do contexto de ensino remoto emergencial. A investigação desses tópicos tem em vista contribuir para a compreensão das singularidades que o Português Língua 
Estrangeira na China enfrentou no meio de tempos conturbados que obrigaram os atores de ensino (instituições, professores e alunos) a encontrarem novas formas de trabalhar e interagir. Tendo em conta a dimensão mundial dessa temática, este estudo pretende também reunir opiniões, experiências e sentimentos dos alunos que possam ser comparados entre diferentes países ou contextos, com o intuito de fornecer uma visão mais abrangente dos problemas que se colocaram ao ensino durante o primeiro confinamento de Covid-19 e das respostas que se podem construir para superar esses desafios comuns.

\section{Ensino Remoto Emergencial}

A pandemia gerou provavelmente a maior ruptura de sempre no plano educativo mundial, afetando diretamente a vida dos indivíduos e as perspetivas das suas comunidades (OCDE, 2020 , p. 4). Nesse contexto, os decisores de educação tomaram medidas inéditas e imediatas para implementar estratégias que atenuassem o impacto educacional da pandemia. Uma vez que as autoridades por todo o mundo decretaram medidas de isolamento e desaconselharam a proximidade física para evitar a propagação do vírus, as instituições educativas tiveram de optar por formas de ensino não presencial. Através da revisão da literatura sobre o tema, verifica-se que o conceito de Ensino Remoto Emergencial (doravante referido como ERE), associado aos tempos de Covid-19, foi um conceito primeiramente introduzido por Hodges et al. (2020). Para esses autores, o ERE carateriza-se por uma mudança temporária para um modo de ensino alternativo devido a circunstâncias de carácter urgente, como crises ou catástrofes. O ERE requer o uso de soluções 
de ensino totalmente remotas que, de outra forma, seriam ministradas presencialmente (ou de forma híbrida), mas que retornarão ao modelo anterior, assim que a crise ou a emergência passar. O objetivo principal, nessas circunstâncias, não é recriar um contexto educacional completo, mas sim fornecer uma alternativa temporária e rápida que seja confiável e fácil de pôr em prática durante um estado de emergência (HODGES et al., 2020 , p. 6). A escolha do termo remoto, ao invés de on-line, para definir esse tipo de ensino, justifica-se pelo fato de o ensino on-line poder ocorrer também no mesmo espaço físico em interação entre professor e aluno, ao passo que o ERE exige um distanciamento físico, uma interação necessariamente remota. Hodges et al. (2020, p. 8) sintetizam também as principais diferenças entre ERE e Ensino a Distância (EaD). O EaD pressupõe a existência de: currículos devidamente planejados e estruturados; cursos originalmente delineados para ocorrer online; uma implementação previamente preparada e organizada em termos de materiais didáticos, acompanhamento dos alunos, avaliação, etc.; contacto presencial sempre que necessário; alto nível de autonomia por parte do aluno, que deve ser orientado por meio de novas estratégias e aprendizagens; preparação dos professores para projetar e facilitar a aprendizagem on-line; o desenvolvimento do processo de $\mathrm{EaD}$ de forma sustentável e proativa. Contrariamente, o ERE define-se pela ocorrência de: pouca ou nenhuma adaptação do currículo ao formato de ensino on-line, uma vez que os cursos não foram desenhados para esse fim; implementação muitas vezes deficitária devido ao caráter urgente e temporário; impossibilidade de interação presencial; falta de preparação específica de professores e alunos; o desenvolvimento do ERE decorre de forma reativa, consoante os problemas e questões que vão surgindo a cada momento. 
A propósito da delimitação teórica entre $\mathrm{ERE}$ e $\mathrm{EaD}$, Gusso et al. (2020, p. 4) defendem que não são categorias dicotómicas com fronteiras definidas, porque, em algumas instituições universitárias, a resposta emergencial aproxima-se mais das caraterísticas do $\mathrm{EaD}$, enquanto, em outras instituições, estabelece-se um ERE pouco estruturado devido à falta de infraestruturas, de recursos, de formação de professores e alunos ou de um plano pedagógico emergencial. Instituições de ensino com diferentes recursos e estruturas viabilizam condições de ensino on-line diferentes, tal como acontece no modo de ensino presencial. Da mesma forma, as condições existentes nas famílias e comunidades também influem na qualidade do ERE, uma vez que se trata de uma situação imprevista para a qual não existe preparação em termos de recursos ou conhecimentos.

Em relação às vantagens que a literatura associa ao ERE, estão a economia de tempo e de deslocações, um maior alcance do ensino, bem como uma maior flexibilidade na aprendizagem. No entanto, a principal mais-valia é o fato de constituir uma alternativa para que o ensino não pare durante um período de crise global. Por esse motivo, durante a pandemia, o foco do ensino remoto não deve estar só na obtenção de resultados de aprendizagem, mas também no desenvolvimento do plano social, emocional e humanitário para proteger a saúde física e mental de alunos e professores (FERRI; GRIFONI; GUZZO, 2020; GUSSO et al., 2020; HUANG et al., 2020; ZHU; LIU, 2020). Para Bozkurt e Sharma (2020, p. iv), o ERE requer a colaboração de diferentes atores (por exemplo, famílias, psicólogos, sociólogos, terapeutas, etc.) porque, em tempos de crise, é imprescindível cuidar e apoiar os alunos, tendo o ensino de conteúdos um papel secundário. Os autores alertam 
para a necessidade de se ensinar como compartilhar, colaborar e apoiar os estudantes em uma época em que se encontram em isolamento, a ter aulas em espaços físicos inapropriados e sob um clima de ansiedade, estresse e pressão psicológica, pois as famílias e as comunidades enfrentam graves problemas.

A literatura apresenta outras dificuldades do ensino remoto, principalmente a carência de dispositivos tecnológicos e o acesso precário à internet, uma vez que a "falta de tecnologia apropriada e de experiência nas plataformas de aprendizagem on-line são os principais desafios enfrentados por educadores e instituições académicas em todo o mundo". (MOHMMED; KHIDHIR; NAZEER, 2020, p. 3). Por outro lado, muitos professores e alunos têm revelado pouca confiança nas estratégias de ensino digitais devido à falta de motivação originada pela perda de interação humana, inclusive a perda de comunicação não verbal estabelecida através das emoções, postura ou expressões faciais (BOZKURT; SHARMA, 2020; FERRI; GRIFONI; GUZZO, 2020; MOREIRA; HENRIQUES; BARROS, 2020). Essa impessoalidade que o ensino remoto introduz é um dos grandes desafios causados pelas alterações das práticas tradicionais de ensino. Embora as relações a distância, independentemente da proximidade física ou espacial, sejam cada vez mais comuns na sociedade de hoje, o mesmo não acontecia no processo de ensino de forma tão notória. É conveniente, porém, sublinhar que a impessoalidade não é um problema exclusivo do ensino remoto, pois existem regiões do mundo onde as salas de aula possuem um elevado número de alunos e a interação entre professor e aluno é reduzida ou inexistente, nomeadamente na China, onde as turmas podem ter várias dezenas ou centenas de alunos, e os métodos de ensino tendem a ser menos comunicativos (CLARKE, 2009; KULICH; WANG, 2015; PIRES, 2019). 
Para além dessa impessoalidade vivida em muitas áreas da vida social e que agora se difundiu no ensino de forma generalizada, outros desafios se colocam ao ensino remoto. Uma vez que a pandemia e as suas consequências se prolongam indefinidamente no tempo, é necessário passar de um ensino emergencial para uma educação em rede, sustentada e bem definida, concebida para fazer pleno uso dos meios on-line a serviço da educação e fazer da sala de aula on-line um "espaço ativo com dinâmicas próprias e não apenas um repositório de conteúdos". (MOREIRA; HENRIQUES; BARROS, 2020, p. 357). Para Moreira, Henriques e Barros (2020), as principais medidas passam por dotar os professores de maior suporte e formação tecnológica, dotar os alunos de mais autodisciplina e autonomia na aprendizagem, ajustar os objetivos curriculares e definir estratégias de avaliação digital. A avaliação dos alunos é também um dos problemas associados ao ensino remoto. Segundo Ferri, Grifoni e Guzzo (2020, p. 15), algumas alternativas para melhorar a questão da avaliação sumativa em ambientes on-line poderão ser trabalhos que os estudantes apresentem ou carreguem nas plataformas digitais ou ainda testes de avaliação automática ou manual, incluindo exames síncronos, em tempo real. Devido à necessidade de uma transição emergente para um ensino on-line sustentado, é necessária uma construção constante e concertada que englobe essas e outras questões, como a equidade e inclusão para garantir que todos os alunos tenham acesso a programas de ensino on-line e o reforço da segurança e da proteção de dados. Refletir sobre todas essas questões é imperativo, pois, tal como argumentam Bozkurt e Sharma (2020, p. iv), as causas das interrupções da educação não se limitam às pandemias. As guerras, conflitos e desastres naturais podem fazer parte da 
agenda futura como potenciais fontes de interrupção e fazer do ensino on-line uma realidade constante.

As caraterísticas temporárias e iminentes do ERE têm consequências na qualidade de ensino, pelo que esta não é uma solução de longo prazo, mas uma resposta provisória para um problema imediato. Na verdade, o ERE é, por vezes, a única solução para que a educação de milhões de estudantes não fique estagnada ou confinada por entre as dúvidas e os receios dos dias atuais. É precisamente a educação e o conhecimento que, agora de forma ainda mais veemente, são imprescindíveis para dar as respostas e apresentar as soluções de que o mundo precisa. Nesse sentido, apesar das precariedades e dos condicionalismos, o Ensino Remoto Emergencial e sobretudo os meios que permitem esse tipo de ensino à escala mundial constituem um símbolo do poder da educação, da ciência e do desenvolvimento da humanidade, possibilitando que a aprendizagem e o conhecimento não parem de avançar no meio de uma crise de proporções colossais. Um produto da educação, lato sensu, a serviço do ensino, que demonstra a capacidade criativa e transformadora que a humanidade precisa para encarar o futuro com esperança.

\section{Metodologia}

Em termos metodológicos, este estudo baseou-se na aplicação de questionários e na realização de entrevistas. Primeiramente, foram aplicados questionários a 12 alunos de uma turma do segundo ano de português, na Universidade de Sun Yat-sen (em maio de 2020), a fim de compreender o impacto das aulas on-line de contingência na perspetiva dos estudantes. 
Com vista a obter os dados de forma mais rápida e completa e a realizar uma análise mais meticulosa dos resultados, os questionários foram elaborados através da plataforma on-line Survey Monkey, especializada nesse tipo de método científico. Após a resposta aos questionários, os mesmos alunos foram entrevistados a distância, durante parte do tempo de uma aula online, com o intuito de aprofundar a discussão sobre os principais tópicos resultantes das respostas aos questionários.

Os questionários contêm 10 perguntas de modo a recolher a visão dos estudantes sobre alguns aspetos cuja literatura sobre esse tema aborda, nomeadamente, as condições de acesso à internet dos alunos, os recursos tecnológicos usados, a preparação e desempenho dos professores para utilizar esse tipo de ferramentas, a motivação dos alunos para a aprendizagem e as mais e menos-valias desse tipo de ensino.

A seleção da amostragem foi facilitada pelo conjunto de pessoas constituído pela turma de alunos, um "agrupamento natural da população previamente formado em que todos os elementos são escolhidos". (SOUSA; BAPTISTA, 2000, p. 76). O questionário contém perguntas fechadas, de escolha simples ou múltipla, entre as respostas alternativas, e questões abertas, em que os participantes respondem com as suas próprias palavras. Trata-se de um questionário de tipo misto, pois o processo de pesquisa é como um mosaico que descreve um fenómeno complexo e que precisa estar aberto a novas ideias, perguntas e dados, servindo-se, para esse fim, de procedimentos qualitativos e quantitativos (GÜNTHER, 2006, p. 202). O nível linguístico foi adequado à amostra, constituída por estudantes com apenas um ano de estudo de português, pelo que se realizou um préteste, que possibilitou rever palavras menos familiares para os 
estudantes, de modo a "evitar a não resposta por incompreensão ou erros graves na recolha de dados". (SOUSA; BAPTISTA, 2000, p. 100). Esse pré-teste permitiu melhorar algumas perguntas e assegurar as condições necessárias para a objetividade, clareza e simplicidade do questionário, a fim de garantir que este seria de fácil preenchimento e bem compreendido pelos estudantes, condições fundamentais para as respostas serem de clara sistematização e análise.

Em relação à entrevista, tratou-se de uma entrevista focalizada, que permitiu um diálogo mais demorado e aprofundado sobre o tema investigado. Segundo Gil (2008, p. 112), esse tipo informal de entrevista é utilizado em situações experimentais, com o objetivo de explorar experiências vividas em condições precisas, dirigindo-se a grupos de pessoas que passaram por uma experiência específica.

Os tópicos da entrevista basearam-se nos principais resultados obtidos dos questionários, tendo sido abordados de forma livre e informal. Os entrevistados trocaram abertamente as suas opiniões sobre os tópicos, e as perguntas seguiram um roteiro semiestruturado, dando liberdade aos entrevistados, sem fugir muito do tema, para recolher informações centradas em um indivíduo ou pequeno grupo, que, "sem limites de tempo ou com ampla liberdade, expõe os seus pontos de vista". (SOUSA; BAPTISTA, 2000, p. 81). Embora alguns entrevistados tenham sido mais participativos, houve convergência quanto aos argumentos apresentados sobre as três temáticas da entrevista (meios tecnológicos e plataformas digitais; interação entre professores e alunos; qualidades e dificuldades das aulas remotas). No decorrer da entrevista, o pesquisador anotou as declarações para posteriormente poder organizar as respostas e 
efetuar uma avaliação global e qualitativa dos tópicos abordados.

\section{Resultados}

Os resultados dos questionários são apresentados seguidamente com as respostas descritas de forma concisa e quantitativa, acompanhadas pelo número de estudantes e respectiva porcentagem:

\begin{tabular}{|c|c|}
\hline Tópicos das perguntas & Respostas \\
\hline P.1 Qualidade do acesso à internet. & $\begin{array}{l}\text { Bom: } 9 \text { estudantes }(75 \%) \\
\text { Razoável: } 3 \text { estudantes }(25 \%)\end{array}$ \\
\hline $\begin{array}{l}\text { P.2 Problemas de comunicação / } \\
\text { compreensão das aulas por causa } \\
\text { da qualidade da internet durante } \\
\text { as aulas. }\end{array}$ & $\begin{array}{l}\text { Sim: } 6(50 \%) \\
\text { Às vezes: } 3(25 \%) \\
\text { Não: } 3(25 \%)\end{array}$ \\
\hline $\begin{array}{l}\text { P.3 Os professores usam métodos } \\
\text { ou conteúdos diferentes nas aulas } \\
\text { remotas. }\end{array}$ & $\begin{array}{l}\text { Não: } 6(50 \%) \\
\text { Sim, conteúdos mais fáceis: } 3 \\
(25 \%) \\
\text { Sim, afastam-se dos conteúdos do } \\
\text { programa, ensinam coisas fora do } \\
\text { plano (cultura, festividades, etc.): } 2 \\
(16,7 \%) \\
\text { Sim, mais informal: } 1(8,3 \%)\end{array}$ \\
\hline $\begin{array}{l}\text { P.4 Mais facilidade em } \\
\text { compreender os conteúdos ou } \\
\text { matérias das aulas. }\end{array}$ & $\begin{array}{l}\text { Aulas presenciais: } 8(66,7 \%) \\
\text { Aulas remotas: } 4(33,3 \%)\end{array}$ \\
\hline $\begin{array}{l}\text { P.5 Mais facilidade em apresentar } \\
\text { questões / colocar dúvidas. }\end{array}$ & $\begin{array}{l}\text { Aulas presenciais: } 7(58 \%) \\
\text { Aulas remotas: } 5(42 \%)\end{array}$ \\
\hline $\begin{array}{l}\text { P.6 Plataformas, aplicações ou } \\
\text { sítios da internet mais usados } \\
\text { (cada aluno poderia referir mais } \\
\text { que um). }\end{array}$ & $\begin{array}{l}\text { Tencent Meeting: 4, Seesaw: 4, } \\
\text { Zoom: } 2 \\
\text { UMU: 3, Yuketang: 2, DingTalk: } 1\end{array}$ \\
\hline
\end{tabular}




\begin{tabular}{|c|c|}
\hline $\begin{array}{l}\text { P.7 Motivação para as aulas } \\
\text { remotas. }\end{array}$ & $\begin{array}{l}\text { Alta: } 1(8,3 \%) \\
\text { Mais do que as aulas presenciais: } 1 \\
(8,3 \%) \\
\text { A mesma do que as aulas } \\
\text { presenciais: } 1(8,3 \%) \\
\text { Menos do que as aulas presenciais: } \\
8(66,7 \%) \\
\text { Baixa: } 1(8,3 \%)\end{array}$ \\
\hline $\begin{array}{l}\text { P. } 8 \text { Performance dos professores } \\
\text { nas aulas remotas. }\end{array}$ & $\begin{array}{l}\text { Melhor do que as aulas presenciais: } \\
2(16,7 \%) \\
\text { A mesma do que as aulas } \\
\text { presenciais: } 9(75 \%) \\
\text { Pior do que as aulas presenciais: } 1 \\
(8,3 \%)\end{array}$ \\
\hline $\begin{array}{l}\text { P.10 Principais características } \\
\text { positivas / vantagens das aulas } \\
\text { remotas. }\end{array}$ & $\begin{array}{l}\text { Poupar tempo (saídas e } \\
\text { deslocações): } 5(41,7 \%) \\
\text { Colocar questões por escrito } \\
\text { ao professor (nas caixas de } \\
\text { mensagens): } 3(25 \%) \\
\text { Rever a matéria (gravações de } \\
\text { aulas): } 2(16,7 \%) \\
\text { Melhorar o uso das ferramentas da } \\
\text { internet: } 1(8,3 \%) \\
\text { O professor pode usar o Google: } 1 \\
(8,3 \%)\end{array}$ \\
\hline $\begin{array}{l}\text { P.10 Principais características } \\
\text { negativas /desvantagens das aulas } \\
\text { remotas. }\end{array}$ & $\begin{array}{l}\text { Falta de interação (ausência de } \\
\text { contacto face a face, perda de } \\
\text { interesse, distrações por conversas } \\
\text { paralelas com colegas ou pelo ruído } \\
\text { em casa): } 7(58 \%) \\
\text { Falta de motivação: } 2(16,7 \%) \\
\text { Causador de preguiça: } 1(8,3 \%) \\
\text { Falhas da internet: } 1(8,3 \%) \\
\text { Ausência de tempo de intervalo } \\
\text { entre aulas: } 1(8,3 \%) \\
\text { Critérios de avaliação complexos: } \\
1(8,3 \%)\end{array}$ \\
\hline
\end{tabular}




\section{Discussão dos resultados}

Após a coleta dos questionários e de efetuada uma leitura geral dos resultados, foram discutidos os principais tópicos com os estudantes, sob a forma de entrevista em mesa-redonda, que decorreu remotamente, durante parte de uma aula de português. Essa discussão, que permitiu aprofundar os resultados, dividiuse nos seguintes três tópicos: meios tecnológicos e plataformas digitais; interação entre professores e alunos; qualidades e dificuldades das aulas remotas.

\subsection{Meios tecnológicos e plataformas digitais}

De forma geral, os alunos disseram ter bom acesso individual à internet, salvo algumas interferências esporádicas. No entanto, os alunos relataram falhas de comunicação durante as aulas que os impediram de ouvir os professores e em que tiveram de desligar a câmaras para garantir a qualidade da conexão. Se a questão do acesso individual à internet não constituiu um problema para o acompanhamento e compreensão das aulas, as dificuldades surgiram com a presença simultânea de várias pessoas na mesma plataforma, o que originou falhas de comunicação que levaram alguns alunos a distrair-se e a perder o foco na aula durante certos períodos. Alguns alunos destacaram o ensino remoto como uma oportunidade para desenvolver conhecimentos informáticos em algumas plataformas on-line e também o fato de os professores poderem recorrer ao Google, cujo acesso não é permitido no campus universitário. Em relação às aplicações mais usadas durante o ensino remoto, destacaram a plataforma chinesa Tencent 
Meeting, com funcionalidades semelhantes à plataforma Zoom, bem como as ferramentas Seesaw, UMU e Yuketang. Entre essas aplicações, as que os alunos mais gostaram de descobrir e explorar foram a Seesaw, que permite fazer pesquisas e apresentar trabalhos em diversos formatos (escrito, áudio, vídeo, etc.), bem como a UMU, que é uma plataforma de ensino com vários recursos, na qual os usuários podem preparar aulas sobre diferentes temáticas, criar atividades que incluem gamificação ou ainda estabelecer critérios de avaliação de acordo com as aulas e atividades efetuadas. Essas plataformas permitiram que os professores colocassem vídeos ou documentos em formato áudio para que os alunos trabalhassem diferentes competências linguísticas, como a compreensão escrita e a compreensão e produção oral. Os alunos fizeram upload da leitura de textos em voz alta e das respostas por oralidade às tarefas solicitadas, pelo que sublinharam o aspeto positivo de trabalharem competências orais e audiovisuais na língua estrangeira.

No entanto, admitiram também um cansaço com essas plataformas e respetivas tarefas no decorrer do semestre, uma vez que representavam trabalho extra para além do tempo das aulas remotas. Em relação ao aplicativo Yuketang, implementado na universidade para vigiar os exames finais, esta serve para efetuar um monitoramento dos alunos em tempo real enquanto fazem o exame. Os alunos referiram que esse aplicativo suscitou algum nervosismo, porque, além de filmar os alunos, notifica imediatamente o professor no caso de se abrir uma página ou programa no computador, o que originou uma pressão adicional sobre os alunos. Esse é um exemplo dos desafios que se colocam a esse tipo de ensino e que é preciso discutir considerando a segurança, privacidade e proteção de dados, tal como defendem Ferri, Grifoni e Guzzo (2020) ou UNESCO (2020b). 


\subsection{Interação entre professores e alunos}

Em relação aos métodos e aos conteúdos de ensino dos professores durante as aulas remotas, os alunos afirmaram não haver diferenças significativas em relação às aulas presenciais, pois utilizaram o mesmo estilo de ensino e os mesmos materiais, como, por exemplo, os manuais didáticos, mas, desta feita, em formato digitalizado. No entanto, sublinharam que os conteúdos das aulas remotas foram mais leves ou fáceis do que as aulas presenciais e que os professores, por vezes, falavam muito sobre algumas temáticas (cultura, geografia, desporto, tradições, etc.), afastando-se dos conteúdos programáticos. Esses argumentos vão ao encontro do que a literatura refere sobre o ERE e a ocorrência de uma transposição imediata do modelo presencial para a plataforma digital sem uma formação prévia de como gerir o tempo de aula ou preparar métodos e materiais específicos. Os alunos revelaram que os professores, por vezes, tinham dificuldades com a tecnologia, porque estavam a utilizar algumas plataformas pela primeira vez e precisaram do suporte dos alunos para se adaptarem às funcionalidades dessas plataformas digitais. Essa dimensão de mútua descoberta e entreajuda entre professores e alunos, no ensino remoto, é um aspecto peculiar na forma como introduz a participação e colaboração no processo de ensino.

Os alunos referiram também a falta de interação com o professor, admitindo ser um fator negativo e desmotivante. Por outro lado, muitos deles reconheceram sentir-se mais à vontade para fazer questões e colocar dúvidas ao professor. Esses alunos afirmaram que, por causa da sua timidez, normalmente, evitam interromper o professor para colocar questões nas 
aulas presenciais, mas, no ensino remoto, fazem-no com mais frequência (e discrição), através das janelas de conversa das aplicações. A impessoalidade, que o ensino remoto pressupõe e que desmotiva alunos e professores, parece encontrar, no seio dos estudantes chineses, um lado positivo. Nas aulas presenciais, os alunos chineses tendem a colocar as questões de forma individual, depois do final da aula, dada não só a personalidade geralmente mais reservada dos alunos, mas sobretudo a própria cultura de aprendizagem chinesa, que recomenda os estudantes a não interromper o professor durante a exposição da aula (JIN; CORTAZZI, 2006; LIU; ZHANG; YIN, 2014; PIRES, 2020).

\subsection{Qualidades e dificuldades do ensino remoto}

Em geral, os alunos revelaram que essas aulas permitem acompanhar as explicações dos professores e os materiais usados (como manuais ou PowerPoints) com mais atenção. No entanto, devido à mudança de ambiente de aprendizagem, de não estarem inseridos em uma turma física nem haver competição entre colegas, disseram que não se sentiam motivados ou que tiveram muitas dificuldades para encontrar alento para estudar. A falta de motivação para estudar foi uma das maiores dificuldades apontadas, aumentando com o decorrer dos meses e levando os estudantes a admitir que, neste semestre, estudaram bastante menos do que o habitual. Os alunos revelaram também o cansaço causado pela quantidade de tarefas e trabalhos que os professores deram ao longo do semestre para além das aulas de ensino remoto. Na perspetiva dos alunos, os professores consideravam o ensino remoto menos exigente e acabavam por dar mais tarefas aos alunos para fazer, algo que os fez sentir sobrecarregados de trabalho. 
Outro dado pertinente é que os alunos revelaram também que o ensino remoto e a conjuntura de pandemia causaram um grande cansaço físico e psicológico e que estudar para os exames foi muito difícil. Os alunos reconheceram ter muitas dificuldades para se focarem na aprendizagem e estabelecerem uma disciplina de estudo. Por esses motivos, alguns admitiram que, por vezes, desempenharam outras atividades enquanto os professores lecionavam as aulas remotas, como jogar computador, arrumar o quarto, falar ao telefone com outras pessoas, etc. Os alunos afirmaram que o controlo ou registo das presenças se baseava apenas no fato de o aluno estar ou não presente na plataforma digital, revelando que, com a câmara desligada, era fácil “enganar" o professor e fazer outras coisas durante o tempo de aula.

Por todas essas razões, os alunos consideraram que a falta de motivação, de interesse ou foco nos conteúdos e de autodisciplina de estudo foi a principal dificuldade encontrada, sobretudo à medida que o semestre avançou e o cansaço em relação às aulas remotas se acumulou. Ressalta-se ainda o caso de dois alunos que ficaram no campus da universidade e que admitiram uma carga de preocupação e cansaço psicológico ainda maior por atravessarem toda essa fase sozinhos, longe das suas famílias. A epidemia na China começou durante o período de férias letivas do ano novo chinês e a grande maioria dos alunos estava nas suas casas, onde permaneceram — segundo ordem das autoridades competentes - durante todo o semestre. Situações como a desses dois estudantes são exemplos claros da necessidade prioritária de cuidar da saúde física e mental dos alunos (BOZKURT; SHARMA, 2020; GUSSO et al., 2020; HODGES et al., 2020). 
Outra questão pertinente, apesar de não fazer diretamente parte do roteiro da mesa-redonda, é o fato de os alunos referirem que, nas licenciaturas de Física, Matemática ou Língua Chinesa da universidade, os estudantes e professores tiveram mais dificuldades com as aulas remotas, uma vez que as turmas desses cursos têm entre 120 a 150 alunos, causando enormes problemas na interação e gestão das aulas remotas e exigindo a divisão de cada turma em vários grupos para viabilizar essa forma de ensino.

Outra desvantagem mencionada na aprendizagem de português, não devido ao ensino remoto, mas pelo contexto de pandemia, foi o fato de os alunos não poderem fazer intercâmbio de estudos, como é habitual, no terceiro ano do curso. Normalmente, os alunos têm a oportunidade de estudar um ano (dois semestres) em instituições de ensino superior de Portugal ou do Brasil, mas, nesse ano, não o puderam fazer, devido às restrições de circulação. Talvez mais do que em outras áreas do saber, a aprendizagem de uma língua é particularmente influenciada pelo contexto de imersão, não só no plano linguístico, mas também no sociocultural. Essa é uma oportunidade que esses alunos não vão ter e que consideram ser uma desvantagem na sua formação académica em relação aos alunos dos anos anteriores, causando alguma desmotivação em face das expetativas criadas em relação à experiência de intercâmbio. No fundo, uma das muitas consequências que os tempos de pandemia têm provocado no ensino superior. 


\section{Conclusões}

Presentemente, os sistemas de educação e as instituições de ensino superior enfrentam algumas das mais impactantes mudanças da sua história. Aproveitando o efeito da pandemia, cuja contingência fez com que o mundo se encontrasse na inesperada necessidade de abraçar o ensino on-line, o desafio que se coloca, na atualidade, é o de fazer a passagem de um ensino emergencial para um ensino a distância, com a devida estrutura e consolidação, que se apresente como complemento regular do ensino presencial e também como alternativa em termos de oferta e de possibilidade de aprendizagem. Nesse contexto, o ensino de línguas estrangeiras partilha os desafios e as dificuldades de outras áreas de ensino e da generalidade dos atores educativos à escala mundial. É de alguma forma assinalável que uma pandemia que teve a consequência de distanciar e apartar as pessoas, trazendo desconfiança e incerteza, tenha também o efeito de apresentar obstáculos e necessidades globais que só podem ser supridas através de esforços comuns delineados em convergência e cooperação. É dessa forma coletiva que se poderá superar a falta de condições ou de recursos de aprendizagem em alguns contextos, fomentar o treinamento pedagógico e tecnológico, trabalhar a adaptação a novos tipos de interações e relações interpessoais que o ensino on-line suscita e dotar os atores educativos de meios e conhecimentos para fazer das plataformas on-line uma mais-valia no processo de ensino. Unir esforços nesse sentido é pertinente para o ensino on-line se libertar cada vez mais do seu lado emergencial, como transposição quase direta de um modelo presencial e expositivo, para adquirir uma identidade própria que fomente a autonomia 
e a construção de conhecimento por parte do aluno e a inovação e criatividade do lado do professor, assumindo este um papel de mediador e menos de expositor de conteúdos.

Na China, o ensino remoto emergencial, motivado pela pandemia, ficou circunscrito a um determinado período de tempo, entre fevereiro e junho/julho de 2020, correspondente ao segundo semestre do ano académico 2019/2020. Desde o início do ano académico seguinte, em agosto de 2020, que as aulas decorrem com normalidade, isto é, presencialmente. Diferentemente de outros países em que as aulas têm estado a decorrer on-line desde o início da pandemia, ou, ainda, de outros países em que, após um interregno, foi retomado o ensino on-line devido ao agudizar da propagação do vírus, na China, talvez por causa de medidas como as restrições nas fronteiras, a monitorização das pessoas através de aplicativos digitais ou a obrigatoriedade de um período de duas a três semanas de quarentena ao entrar no país, tem-se verificado um maior controlo da propagação do vírus, com a inexistência ou ocorrência muito residual de casos de transmissão. Esses fatores fazem com que a vigência do ensino remoto emergencial esteja, até à data, circunscrita apenas aos já referidos meses de 2020. No entanto, há algumas decorrências que o ensino emergencial estimulou e cuja presença se pode verificar empiricamente no ensino presencial da Universidade de Sun Yat-sen, tais como: o crescimento do uso de plataformas on-line para explorar conteúdos, preparar apresentações ou fazer os trabalhos de casa, nomeadamente DingTalk, UMU ou Seesaw, que permitem trabalhar com materiais didáticos em diferentes tipos de formato (vídeo, música, etc.); a transmissão de aulas em direto para alunos que não podem estar presentes na sala de aula por razões de força maior, nomeadamente, os estudantes 
internacionais que ainda não estão autorizados a entrar no país; a gravação de aulas que possibilita aos alunos estudar e rever as matérias posteriormente; o uso mais frequente de aplicativos através dos quais os alunos discutem os temas entre si ou apresentam dúvidas e colocam questões aos professores; o papel mais participativo e significativo da vertente on-line com possíveis reflexos na avaliação final dos alunos.

$\mathrm{O}$ ensino remoto emergencial intensificou o papel da tecnologia no ensino, possibilitando novas vias para a descoberta e para a interação entre professor e aluno. Por esses motivos, o ensino remoto emergencial não introduz um contraste ou oposição entre aulas digitais e aulas presenciais, mas precipita uma compatibilidade ou complementaridade entre físico e digital que tem necessariamente de se continuar a construir. Os alunos têm na implementação regular da tecnologia um meio através do qual se podem expressar, interagir e explorar as suas necessidades de aprendizagem. A valia dos professores é destacada pela tecnologia, ao expandir os limites da sala de aula e desenvolver novas formas de ensinar e de chegar aos alunos. A tecnologia não ameaça o papel do professor nem a sua importância, pelo contrário, ajuda o professor a reunir mais competências para representar uma fonte ainda mais abundante de motivação e inspiração para os alunos de hoje e de amanhã. A pandemia demonstrou que, apesar da flexibilidade e acessibilidade que as tecnologias permitem, o ensino on-line é complexo e altamente exigente para estudantes e professores. Talvez por esse motivo os alunos tenham afirmado, na entrevista, de forma convergente e concludente, que o presencial nunca poderá ser substituído pelo on-line. 
Vivem-se tempos singulares de reinvenção e de criação de novos modelos de organização social, educativa e profissional. Depois de atravessada essa crise, as universidades não vão prescindir dos esforços e investimentos realizados. A sociedade e o ensino, em particular, precisam da tecnologia como meio transformador e inclusivo que represente um aliado em prol da educação, da solidariedade, da interação e da conexão humana, valores particularmente importantes e prementes nos dias que correm.

\section{Referências}

BOZKURT, A.; SHARMA, R. C. Emergency remote teaching in a time of global crisis due to CoronaVirus pandemic. Asian Journal of Distance Education, [s. l.], v. 15, n. 1, p. i-vi, apr. 2020.

CLARKE, J. Student centred teaching methods in a Chinese setting. Nurse Education Today, [s. l.], n. 30, p. 15-19, jul. 2009.

EDER, R. The remoteness of remote learning: a policy lesson from COVID19. Journal of Interdisciplinary Studies in Education, [s. l.], v. 9, n. 1, p. 168-171, may 2020. Disponível em: <https://www.ojed.org/index.php/jise/article/view/2172>. Acesso em: 2 out. 2020.

FERRI, F.; GRIFONI, P.; GUZZO, T. On-line learning and emergency remote teaching: opportunities and challenges in emergency situations. Societies, [s. l.], v. 10, n. 4, p. 1-18, nov. 2020.

GIL, A. C. Métodos e técnicas de pesquisa social. 6. ed. São Paulo: Atlas, 2008. 
GÜNTHER, H. Pesquisa qualitativa versus pesquisa quantitativa: esta é a questão? Psicologia: Teoria e Pesquisa, [s. l.], v. 22, n. 2, p. 201-210, ago. 2006.

GUSSO, H. et al. Ensino Superior em tempos de pandemia - diretrizes à gestão universitária. Educação e Sociedade, Campinas, v. 41, p. 238-957, 2020. Disponível em: $<$ https://www.scielo.br/scielo.php?script=sci_arttext\&pid $=$ S0101-73302020000100802>. Acesso em: 30 set. 2020 .

HODGES, C. et al. The difference between emergency remote teaching and on-line learning. Educause Review, Washington, mar. 2020. Disponível em: <https://er.educause. edu/articles/2020/3/the-difference-between-emergency-remoteteaching-and-on-line-learning>. Acesso em: 26 set. 2020.

HUANG, R. H. et al. Handbook on facilitating flexible learning during educational disruption: the Chinese experience in maintaining undisrupted learning in COVID-19 outbreak. Beijing: Smart Learning Institute of Beijing Normal University, 2020.

JIN, L.; CORTAZZI, M. Changing Practices in Chinese Cultures of Learning. Language, Culture and Curriculum, [s. l.], v. 19, n. 1, p. 5-20, 2006.

KULICH, S.; WANG, Y. Intercultural communication in China. In: BENNETT, J. (ed.). The SAGE Encyclopedia of Intercultural Communication. Thousand Oaks, CA: SAGE, 2015. p. 458-469.

LIU, Y.; ZHANG, M.; YIN, Q. Challenges in intercultural language education in China. Canadian Social Science, [s. l.], n. 10, v. 6, p. 38-46, ago. 2014.

MOHMMED, A. O.; KHIDHIR, B. A.; NAZEER, A.. Emergency remote teaching during Coronavirus pandemic: the current trend and future directive at Middle East College Oman. Innovative Infrastructure Soluions, [s. l.], n. 5, v. 72, p. 14-27, jul. 2020. 
Disponível em: <https://link.springer.com/article/10.1007/ s41062-020-00326-7\#citeas>. Acesso em: 14 out. 2020.

MOREIRA, J.; HENRIQUES, S.; BARROS, D. Transitando de um ensino remoto emergencial para uma educação digital em rede, em tempos de pandemia. Dialogia, [s. l.], n. 34, p. 351364, abr. 2020.

OCDE. A framework to guide an education response to the COVID - 19 pandemic of 2020. [S. l.], 2020. Disponível em: $<$ https://www.hm.ee/sites/default/files/framework_guide_ v1_002_harward.pdf $>$. Acesso em: 4 out. 2020.

PIRES, M. Gaokao: far more than an exam. Revista Diadorim, [s. l.], Esp. 21, p. 165-184, dec. 2019.

PIRES, M. J. A cultura chinesa: das dimensões culturais de Hofstede às perspectivas asiacêntricas de comunicação. Anuario Latinoamericano - Ciencias Políticas y Relaciones Internacionales, [s. l.], v. 10, p. 147-166, dec. 2020.

SOUSA, M.; BAPTISTA, C. Como fazer investigação, dissertações, teses e relatórios - segundo Bolonha. 3.ed. Lisboa: Edições Lidel, 2000.

UNESCO. COVID-19 Educational disruption and response. 2020a. Disponível em: <www.iiep.unesco.org/en/covid-19educational-disruption-and-response-13363>. Acesso em: 29 set. 2020.

UNESCO. Distance learning strategies in response to COVID-19 school closures. UNESCO COVID-19 Education Response Education Sector issue notes, issue note n. 2.1,2020b. Disponível em: $\quad<$ https://unesdoc.unesco.org/ark:/48223/pf0000373305>. Acesso em: 29 set. 2020.

ZHU, X.; LIU, J. Education in and after Covid-19: immediate responses and long-term visions. Postdigital Science and Education, [s. l.], v. 2, n. 10, p. 695-699, abr. 2020. 